\title{
Estereotipos de género en las escuelas normales. Indicios de una pedagogía sexista
}

\section{Gender stereotypes in the normal schools. Clues of a sexist pedagogy}

Sandra Vega Villarreal ${ }^{1}$

\section{Resumen}

El presente estudio incursiona en las nociones símbolos, imágenes o ideas preconcebidas culturalmente que determinan formas de interacción social. Consiste en un diagnóstico estatal de corte cuantitativo realizado en las Escuelas Normales de Chihuahua. Se operacionalizó a través de una basada en escala Likert, con posibilidades descriptivas y correlacionales. Los estereotipos que están presentes en los estudiantes normalistas muestran la preexistencia de actitudes atribuidas a las mujeres como el ser conflictivas y problemáticas, de ahí que no se les encuentre idóneas para asumir puestos de importancia directiva. Los resultados muestran también que el liderazgo en la autoridad pedagógica se les adjudica a los varones para trabajar en grupos superiores, dada la fragilidad y poca capacidad de imponer la autoridad de las mujeres, quienes son consideradas en otras actividades escolares como el sexo débil. Al cuestionar las agresiones de género, la respuesta conduce a que es culpa de las mujeres por su forma de vestir y conducirse. Con respecto a los roles de género y la paternidad, el estudio muestra que el embarazo es un factor de riesgo académico pero sólo para las mujeres, a los hombres se les exenta, sin embargo, se les da el rol de proveedores. El análisis de los estereotipos que proyectan los estudiantes normalistas nos dan indicios sobre el tipo de pedagogía que se está incubando. Se evidencia la formación de una ciudadanía conservadora, proactiva del sexismo y la segregación de las mujeres, que contribuye a fortalecer la sociedad patriarcal y hegemónica.

1 Sandra Vega Villarreal. Docente-investigadora en la Universidad Pedagógica Nacional del Estado de Chihuahua, Campus Chihuahua, México. Doctora en Educación por la Universidad de Tijuana. Socia del COMIE, REDMIIE y REDIECH. Correo electrónico: svegavillarreal@gmail.com

ID: http://orcid.org/0000-0002-7638-1300 
RECIE. Revista Electrónica Científica de Investigación Educativa Vol. 4, núm. 2, enero-diciembre 2019, pp. 1291-1302.

\title{
Palabras clave
}

Estereotipos, género, escuela, pedagogía.

\begin{abstract}
This reseach studies the notions, images, and culturally preconceived ideas that affect the social interactions. It is a diagnosis to state to Chihuahua, realiced in Normal schools. The research did based in a Likert scale, whith descriptives and correlationals possibilities. The gender stereotypes are into the students, and they reflected in attitudes by women and men, like problems and conflicts. There are others attitudes in order to management positions. The study shows how the leadership in schools is a property to the men. They can to work whith older students, because they are strong. The women are considered the frágil sex. In the questión about the causes to gender violence, the students said that the women are attacked because them inappropriate dress. About the gender roles, they identify a scholar risk only for the women with the pregnance. The man are providers. In the análisis, the gender stereotypes show us a traditional pedagogy in wich are legitimed sexism and patriarcal society.
\end{abstract}

\section{Keywords}

Stereotypes, gender, school, pedagogy.

\section{Introducción}

Las Escuelas Normales son instituciones donde se gestan procesos educativos que impactan directamente en la formación de ciudadanos de un determinado tipo de sociedad. Por tanto, estudiar diversos fenómenos que permean los procesos formativos en estas instituciones brinda elementos para develar procesos pedagógicos existentes y delinear modelos educativos más adecuados a la realidad que se vive. De ahí que, cuestionar cuáles son los estereotipos de género que atraviesan la percepción de los estudiantes normalistas sobre sí mismos, su formación y su desempeño como futuros educadores, proporciona pistas de la visión pedagógica que están construyendo y seguramente implementarán en su futura práctica educativa. Esto proporciona pautas a las Escuelas Normales para delinear una formación de maestros basada en una cultura a favor de la equidad como medio para alcanzar la igualdad de género.

Los estereotipos de género aluden a los imaginarios que gestan, dan forma y legitiman el desarrollo de determinadas prácticas, actitudes y obligaciones de los sujetos ante la vida cotidiana, pues implican el desarrollo 
de actividades, la creación intelectual de los sujetos, así como el desarrollo afectivo, del lenguaje, las concepciones, los valores, las fantasías y los deseos que constituyen su identidad. Esto determina su capacidad para vivir, su posición social y las formas en que se relaciona con los otros.

Este estudio busca rescatar la presencia de los imaginarios presentes en la visión de los estudiantes sobre los procesos formativos que viven, sobre la relación pedagógica que establecen con los programas educativos que cursan y con las miradas que tienen sobre su futuro desempeño como maestro. El análisis de estos estereotipos de género puede aportar elementos para conocer cómo se están construyendo los procesos pedagógicos y delinear en qué medida, éstos legitiman o se distancian de prácticas sexistas, las cuales, generan una interacción nociva, caracterizada por la discriminación y la desigualdad de género, misma que podría cobrar forma en su futura práctica como maestros.

Para la proyección del diagnóstico, se acudió a indicadores relacionados con roles designados culturalmente a funciones específicas para hombre y mujer. Liderazgo legitimado que da a uno de los sexos la autoridad para participar en determinadas acciones. La función reproductiva en hombres y mujeres, así como el ejercicio de la sexualidad y normas de conducta generalizables de acuerdo a la edad y el sexo. Todo ello inmerso en la opinión que expresan los estudiantes sobre ellos mismos, su formación y si ideal de futuro maestro.

\section{Estereotipos de género. Algunas consideraciones para su estudio}

La investigación se propuso realizar un diagnóstico sobre estereotipos de género en las Escuelas Normales del estado de Chihuahua. Se trata de un estudio descriptivo de corte cuantitativo, que dio cuenta del estado que guarda la equidad de género, representada en los estereotipos que reconocen los estudiantes normalistas en sus interacciones diarias.

El estudio buscó recuperar información a través de un instrumento de medición confiable, basado en escala Likert, que aportara un panorama sobre la desigualdad y discriminación de género que pudieran enfrentar los estudiantes, y delinear las pautas de acción en busca de la equidad. Por la dimensión del universo de estudio se determinó una muestra estadística estratificada proporcionalmente, cuyos resultados puedan ser generalizables a la población total.

Algunas nociones teóricas que vertebraron el análisis de la información se desprenden de una visión crítica de la división social que la sociedad patriarcal - capitalista se ha empeñado en preservar. De ahí que los estereotipos de género sean considerados como el rol de género se configura 
con el conjunto de normas y prescripciones que dictan la sociedad y la cultura sobre el comportamiento femenino o masculino, lo que lleva a la construcción de tipos ideales (Weber, 1984), que fomentan ciertos imaginarios en los grupos sociales, por lo que genera y legitima el desarrollo de determinadas prácticas, actitudes y obligaciones que se imponen de acuerdo a este imaginario a través de aparatos ideológicos de Estado que coadyuvan a la cohesión y mantenimiento del orden social.

Los estereotipos de género desde una perspectiva crítica, hace evidente la discriminación como un fenómeno inherente a los mismos, dado que al privilegiar los constructos culturales que responden al tipo ideal weberiano, legitiman la desigualdad de raza, género y clase social y naturalizan la opresión. De ahí que su principal móvil sea una pedagogía bancaria basada en un proceso transmisión y recepción pasiva de conocimientos, que frena todo proceso de actividad creativa, reflexiva y encamina hacia la adaptación de una sociedad ya establecida, centrada en intereses de clase, raza y género que desde el patriarcado se consideran superiores.

\section{Estereotipos en actitudes propias de hombres y mujeres}

Dentro de los imaginarios de una sociedad que divide lo masculino y femenino se atribuyen rasgos de personalidad, formas de ser hombres y mujeres. Al cuestionar a los estudiantes sobre su opinión respecto a si quienes eran más conflictivos y chismosos, que desde argumentos segregacionistas, entorpece el desarrollo institucional. Su respuesta fue contundente

Gráfica No. 1

Actitudes y rol de género

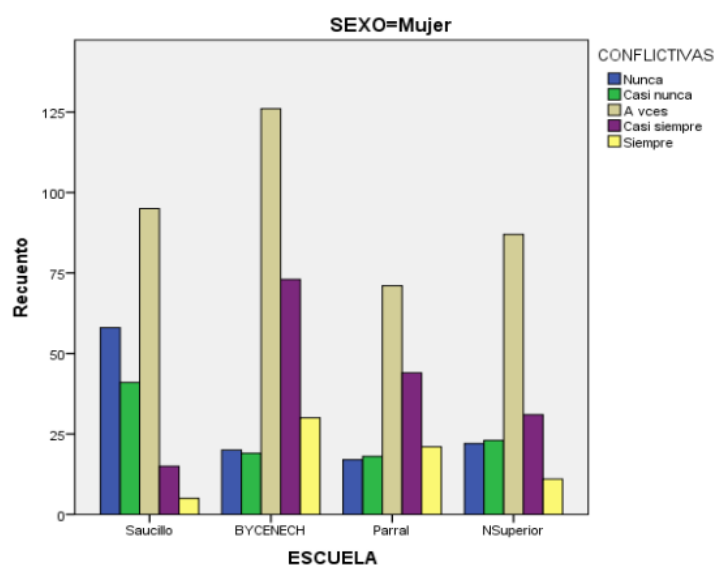

Vega Villarreal, S. 
La gráfica anterior da cuenta de la gran tendencia de que actitudes como el generar conflictos en los espacios escolares es más un atributo de las mujeres que de los hombres. Esto se vio aún más marcado en los imaginarios de las estudiantes mujeres que en los varones. Habría que profundizar en esta percepción como parte de un imaginario social (Castoriadis, 1993) a partir del cual, las mujeres se perciben a sí mismas de forma peyorativa, como un ser menos calificado en la sociedad por características personales que se le han atribuido y ellas mismas la reproducen, tal como la característica de chismosas

Gráfica No. 2

Actitudes según género

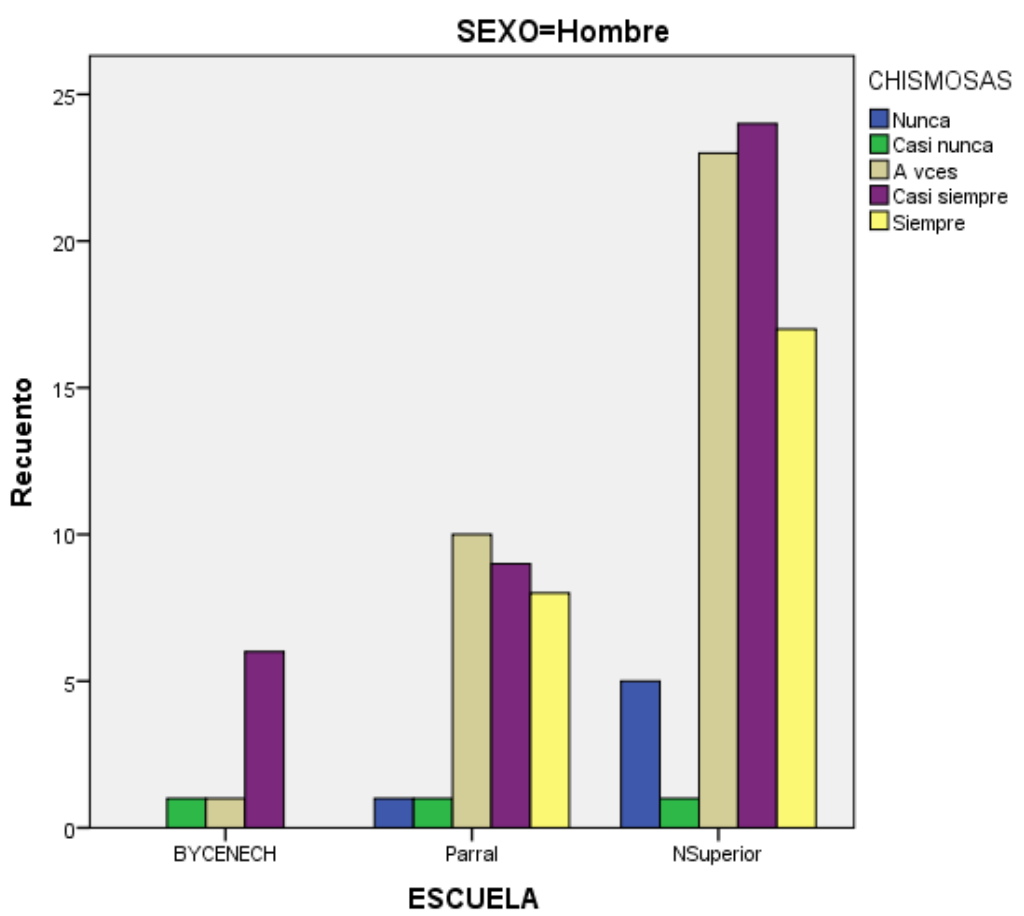

Entre los atributos peyorativos sobre la figura social de la mujer, se encuentra el hecho de comunicar en exceso o compartir sucesos que según la sociedad patriarcal debería permanecer en secreto. De ahí que históricamente, por comunicar, las mujeres hayan sido un blanco de la caza de brujas (Federici, 2004). Por tanto, cuando las creencias de los estudiantes normalistas avalan esta verdad, están legitimando la opresión de género ancestral. Como se puede ver en las siguientes gráficas esta creencia está más arraigada en las mujeres que en los hombres, pues aunque los varones de las escuelas Normal 
Parral y Normal superior embonan con la percepción de las mujeres, los varones de la IBICENECH hacen la diferencia, pues solo algunos de ellos opinan que a veces sucede esto, pero los demás opinan que nunca y casi nunca, por lo que discrepan del estereotipo de que las mujeres son más chismosas que los hombres.

\section{Estereotipos y agresiones de género}

Dentro de los efectos concretos de los estereotipos en la vida cotidiana se vive la re-victimización de las mujeres objeto de acoso sexual, siendo éste uno de los elementos centrales de las luchas feministas actuales. Al cuestionar a los estudiantes si consideraban el vestido de las mujeres como un factor que favorece el hecho de que les dirijan insinuaciones de carácter sexual, que les falten al respeto, las respuestas de los varones resultan preocupantes.

\section{Gráfica No. 3 Provocaciones de mujeres}

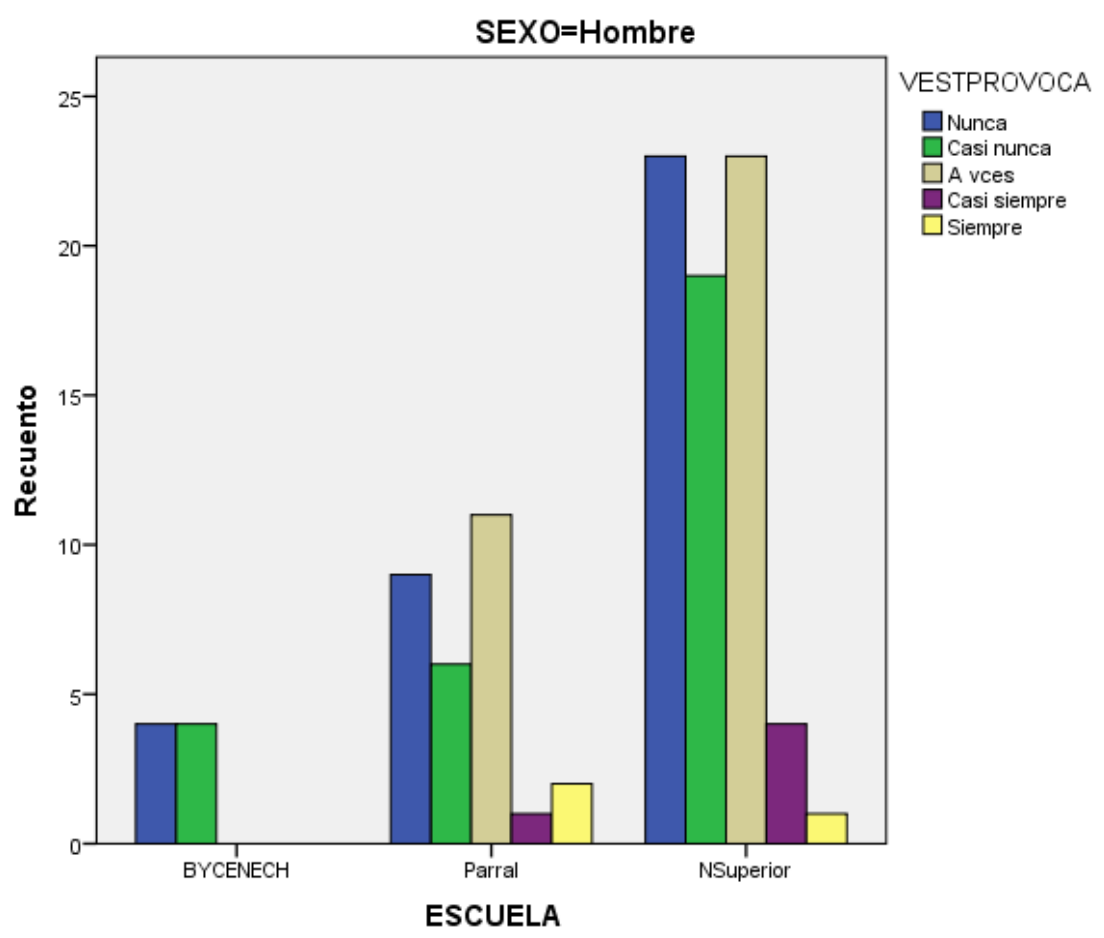


Es en estas expresiones donde podemos localizar uno de los indicios nodales del patriarcado arcaico, que no excluye a las mujeres, pero que analizando la respuesta desde los hombres es muy claro como los varones de IBYCENECH son contundentes en no considerar el vestido como una provocación a las agresiones de género. Sin embargo en Normal Parral y Normal Superior, aunque la mayoría niega esta premisa, se encuentra casi a la mitad de la población masculina legitima esa creencia machista y misógina, que revictimiza a las víctimas de la violencia de género (Lamas, 2013).

\section{El estereotipo de la maternidad y la actividad escolar}

Como parte de uno de los derechos que se han conseguido con luchas feministas, es el ámbito reproductivo. No obstante fue necesario conocer cómo lo perciben los estudiantes normalistas desde su experiencia cotidiana, más como vivencia que como opinión.

La pregunta concreta hurgaba el asunto del embarazo como un factor obstructivo de los procesos educativos que viven los profesores en formación. Las respuestas entre hombres y mujeres fueron muy diferentes, en cierta forma determinados por cómo asumen este rol.

\section{Gráfica No. 4 Género y embarazo}

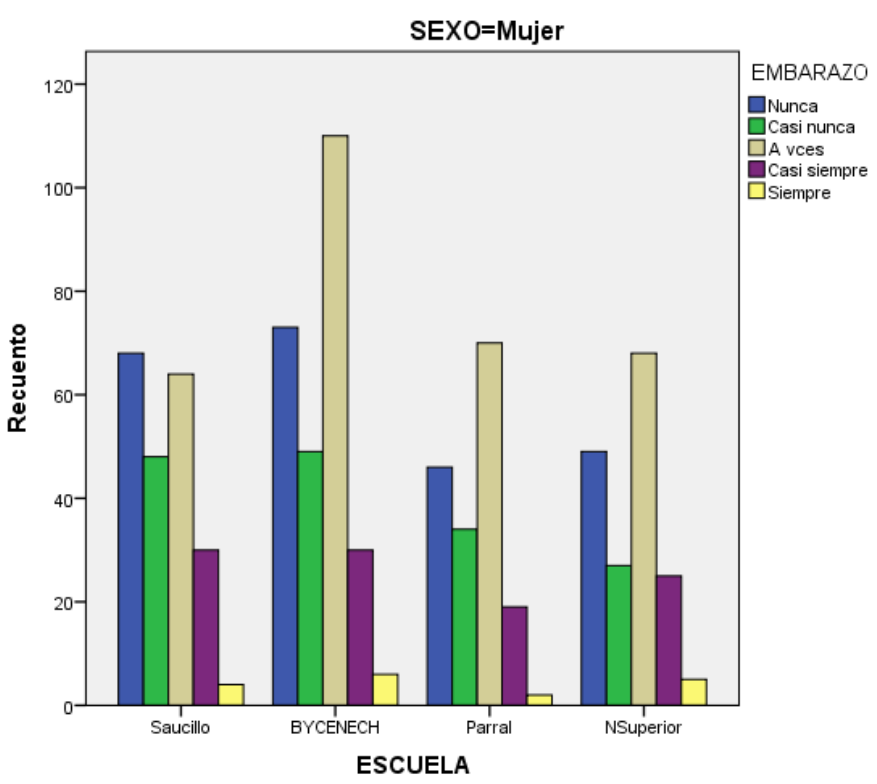

Desde la experiencia de las mujeres, la mayoría de ellas reconoce que las mujeres que estudian y se embarazan tienen más dificultades para transitar por la carrera, incluso este sector de la población expresa haber presenciado 
la exclusión de estudiantes de actividades escolares por embarazo. Cabe destacar que un amplio sector dice que nunca o casi nunca sucede. Estas estudiantes son un sector minoritario. Para la mayoría de los varones encuestados, el embarazo no es considerado un factor de exclusión escolar. Esta respuesta se puede interpretar de diversas maneras, sobre todo reconociendo que aunque es partícipe de este proceso, no es quien lo vive directamente, por lo que sus visiones al respecto son opiniones, mismas que desde la perspectiva de género puede ser un deseo de legítima defensa hacia el derecho de las estudiantes a embarazarse sin ser excluidas o eliminadas del espacio escolar, aspecto que por lo menos en Chihuahua se está impulsando fuertemente desde los tres niveles de Gobierno y de diversas instancias educativas y sociales (LGAMVLV, 2007).

\section{Estereotipos en las figuras legítimas de autoridad pedagógica}

Con la finalidad de identificar las creencias culturales de los estudiantes con respecto a las figuras de liderazgo en la realización de diversas tareas de su formación como docente, de acuerdo al género, se les cuestionó sobre a quienes con más autoridad para el trabajo con grupos superiores, se les propuso explícitamente si los hombres eran más idóneos. Por las características de sus respuestas véase ambas gráficas por género.

\section{Gráfica No 5 Autoridad legítima}

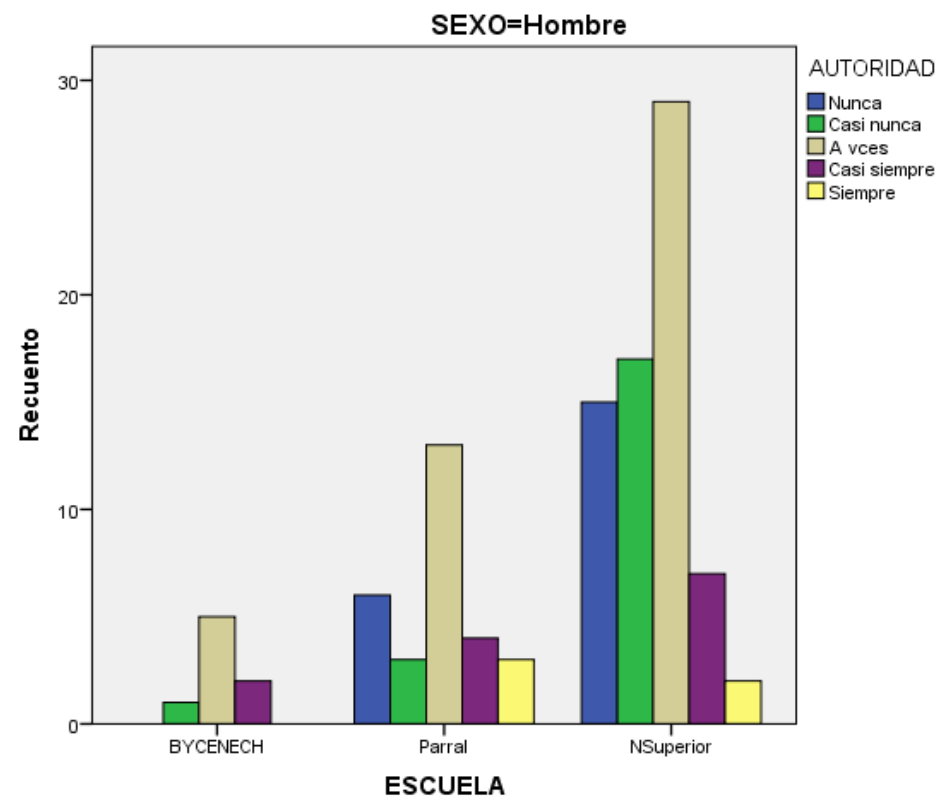

Vega Villarreal, S. 
Al cuestionar sobre qué sexo se considera idóneo para el trabajo con grupos superiores, por aquello de la prenoción que son los que requieren el ejercicio de la autoridad en una faceta más dura, exigente o estricta en términos de disciplina escolar o actividades donde se evidencie el poder del sujeto, la capacidad para vivir, posición social, jerarquías estatus, relación con otros.

Sin embargo, existe una marcada tendencia en los varones de considerarse como la figura ideal para ejercer el liderazgo pedagógico ante los estudiantes. Esto nos puede llevar a considerar dos aspectos importantes, El primero tiene que ver con una visión patriarcal donde el hombre pasa a ser el líder de la sociedad, con lo que además de fortalecer su poder, garantiza su hegemonía. Cuestión que surgió desde la constitución original de la familia patriarcal, la sociedad privada y el Estado (Engels, 2017). Pero también se legitima una visión pedagógica heteroestructuralista (Not, 1983) desde la cual, debe existir una jerarquía en la relación con los estudiantes, donde el líder o mejor dicho el profesor, establece un conjunto de normas de comportamiento coherentes y que garanticen que el currículo a enseñar deberá ser asimilado por los estudiantes. Para ello, este sector de la población estudiada, dibuja en sus imaginarios la figura de un hombre.

No obstante, se planeó en este mismo rubro una pregunta par, que diera más indicios sobre este estereotipo de género, pero con una lógica inversa en la visión sobre el liderazgo pedagógico de los hombres. Para ello se aludió a su desempeño como docente en un grupo de educación preescolar, es decir con estudiantes pequeños, que según el estructural funcionalismo y la distribución de roles sociales, corresponde a las mujeres por su instinto maternal (Parsons, 1985). Las respuestas fueron las siguientes.

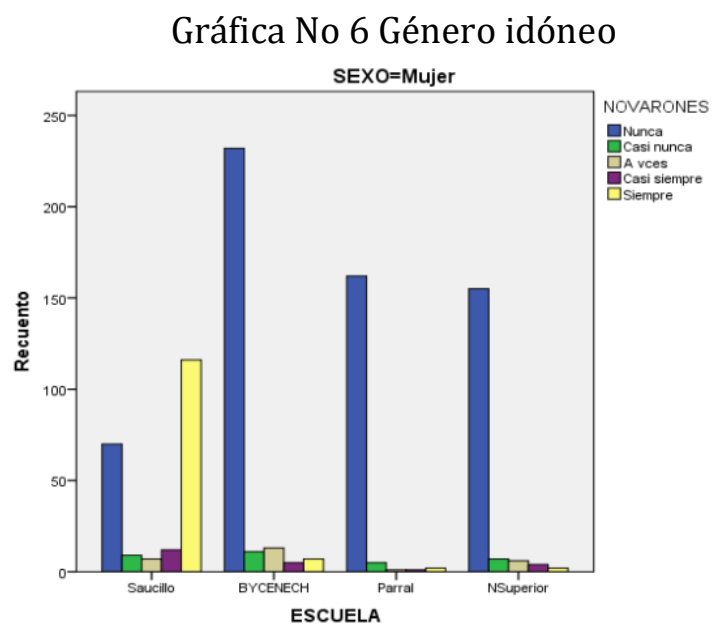

Estereotipos de género en las escuelas normales. Indicios de una pedagogía... 
Como muestran las gráficas, hombres y mujeres consideran que no se ha discriminado a los varones negándoles el acceso a licenciaturas de nivel preescolar por creer que son especialmente para mujeres. Esto rompe con ese mito funcionalista de las mujeres. Se aprecia que los hombres no mantienen congruencia entre las dos respuestas. En las mujeres de Normal Saucillo cambian de opinión, se pudiera considerar que en su escuela no asisten los varones.

\section{Estereotipos sociales en la formación de los normalistas}

Existen en nuestra sociedad una serie de aparatos ideológicos de Estado (Althusser, 1988) que coadyuvan a reproducir construcciones culturales predominantes, que responden generalmente a interés de la clase en el poder. En el ámbito de las concepciones de género implica las actividades y creaciones de los sujetos, el hacer en el mundo, la intelectualidad y la afectividad, el lenguaje, concepciones, valores, el imaginario, las fantasías, los deseos.

Tratando de profundizar en este aspecto, planteamos a los estudiantes dos cuestiones al respecto. La primera se les preguntó si consideraban que las actividades escolares que impliquen trabajo pesado deberían de asignarse a los hombres, dado que ellos deben realizar actividades de esta índole. Las respuestas en hombres y mujeres fueron muy similares, las ilustra la siguiente gráfica.

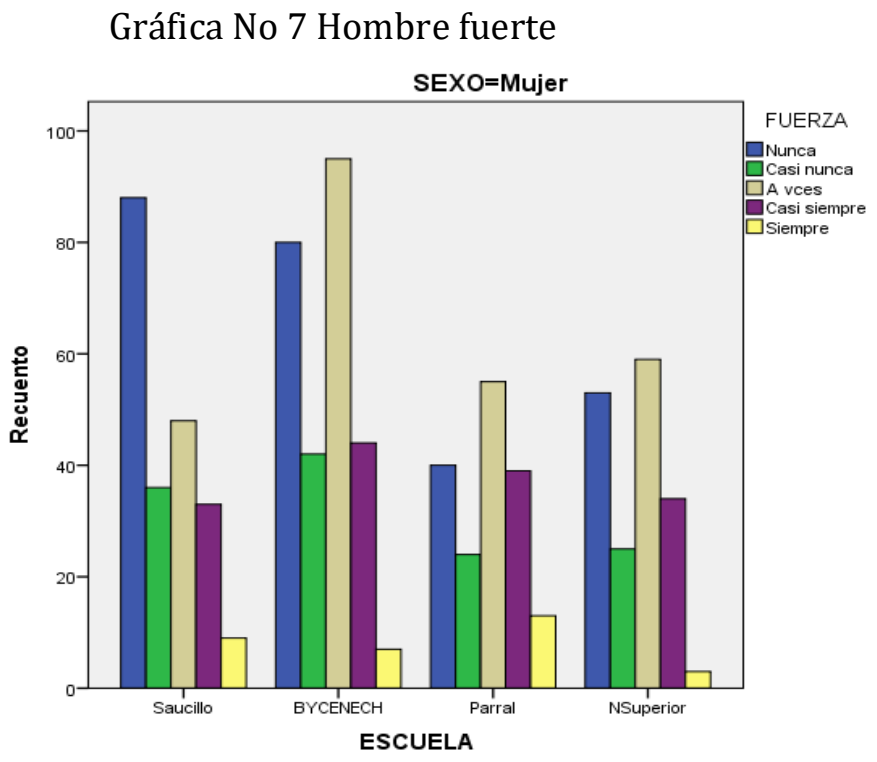

Vega Villarreal, S. 
La ilustración muestra cómo de forma contundente los estudiantes apuestan a que los hombres son el sexo fuerte, por lo menos físicamente y ven como algo natural que a ellos les sean asignados trabajos y actividades que ameriten fuerza. Por tanto, avalan el estereotipo clásico del patriarcado, que bajo una lógica darwiniana establece la diferenciación de género que trasciende el ámbito biológico y justifica en gran manera la segregación política, cultural, social y económica de las mujeres en una sociedad capitalista como la nuestra (Federici, 2004).

En otros indicadores similares se cuestionó de forma directa si consideraban a las mujeres como el sexo débil, la respuesta fue una negación rotunda. La mayoría de los estudiantes dice que nunca y casi nunca sucede eso. Sin embargo, en todas las instituciones hubo una presencia considerable de alumnos que dicen que si es mejor el trabajo de los hombres.

Cuando los estereotipos de género que están presentes en nuestras opiniones se muestran de forma abierta, directa, no pueden más que negarse, pues implica reconocernos a nosotros mismos como instrumentos de opresión social y generadores de desigualdades de género, raza o clase social que impone la sociedad patriarcal a través de diversos aparatos y procesos de enculturación (Lamas, 2002).

\section{Conclusiones}

Elaborar un diagnóstico sobre estereotipos de género en las Escuelas Normales de Chihuahua brinda elementos para impulsar desde la formación docente la construcción de una ciudadanía crítica para una sociedad libre de sexismo y discriminación de raza y género.

Los resultados del estudio proponen revisar la igualdad de género en el acceso a sus programas educativos, incidiendo en el análisis pedagógico de que, en primera instancia no debe existir una figura pedagógica que impone su autoridad, sino que existe un profesor capaz de generar diálogo y relaciones democráticas con sus estudiantes sin importar el sexo, las preferencias sexuales y los roles que desarrollan más allá del aula. Esto posibilitará la ruptura con estereotipos que simplifican las conductas, las condiciones personales y profesionales de los futuros docentes.

Este diagnóstico muestra que un pendiente en la agenda de las Escuelas Normales, la revisión exhaustiva de las implicaciones sociales que subyacen a los modelos pedagógicos que prevalecen en la visión de los estudiantes con respecto a los estereotipos de género., que al ser analizados desde una perspectiva crítica, hicieron patente los constructos culturales que responden al tipo ideal weberiano, los cuales, legitiman la desigualdad de raza, género y clase social y naturalizan la opresión. 
Romper con la visión pedagógica funcionalista y sexista será posible, solamente a través de la generación de prácticas de denuncia, de construcción de resistencias, donde se busque la equidad como medio para la igualdad desde el acto pedagógico, pues no es posible concebir una pedagogía democrática, si no lucha por erradicar el sexismo y la desigualdad que impera en una sociedad patriarcal. Por tanto, si queremos cambiar la sociedad debemos construir una pedagogía no sexista, no discriminatoria, incluyente e igualitaria. De ahí que la formación docente sea el espacio ad hoc para ello.

\section{Referencias}

ALTHUSSER, L. (1988). Ideología y aparatos ideológicos de Estado, México: Siglo XXI Editores

CASTORIADIS, C. (1993). La institución imaginaria de la sociedad, México: Editorial Tusquets.

FEDERICI, S. (2004). Calibán y la bruja. Madrid: Creative Commons.

Ley General de acceso de las mujeres a una vida libre de violencia. (2007). Violencia de género en México. México: CEAMEG.

LAMAS, M. (2002), La antropología feminista y la categoría género, en Cuerpo, Diferencia Sexual y Género. México: Taurus,

LAMAS, M. (2013). El género. La construcción cultural de la diferencia sexual. México: Porrúa.

NOT, L. (1983), Las pedagogías del conocimiento, México, Fondo de Cultura Económica.

PARSONS, T. (1985), La educación como asignadora de roles y factor de selección social, en María de Ibarrola (1985), Las dimensiones sociales de la educación, México: Ediciones El Caballito

PICCINI, M., Nethol, A. M. (2000), Introducción a la pedagogía de la comunicación, México: Editorial Trillas.

ENGELS, F. (2017). El origen de la familia, la propiedad privada y el Estado. Archivo Marx-Engels de la Sección en Español del Marxists Internet Archive (www.marxists.org).

WEBER, M. (1984): La acción social: Ensayos metodológicos. Barcelona: Península. 